\title{
Analizando la modernización en regadíos tradicionales del oeste argentino
}

\author{
Fernando Gonzalez-Aubone, Omar Miranda, Federico Montenegro y Jimena Andrieu \\ INTA (Instituto Nacional de Tecnología Agropecuaria) \\ gonzalez.fernando@inta.gob., armiranda.omar@inta.gob., arfedericoamon@gmail.com, andrieu.jimena@inta.gob.ar
}

\begin{abstract}
Resumen. El Valle del Tulum, en la provincia de San Juan, es uno de los mayores regadíos tradicionales del oeste argentino. De origen prehispánico en el siglo XII este oasis alberga una población de unos 600.000 habitantes, concentrando el $90 \%$ del total provincial. Sus 120.000 ha de concesiones de riego agrícola conforman un complejo agro-ecosistema donde los regantes aún se llevan más del $90 \%$ de las asignaciones de agua y cuentan con derechos fuertemente consolidados; inseparables de la propiedad de la tierra, irrevocables y a perpetuidad. En este contexto conservador las modernizaciones en el sistema de riego se han centrado a nivel de grandes obras hidráulicas, en un extremo, y parcelario, en el otro. Por distintas razones, la Acción Colectiva en la gestión comunera del agua, ha quedado marginada y los cambiostanto institucionales como tecnológicos, se han visto rezagados. Bajo esta situación, este trabajo ha tomado una unidad administrativa (Comisión de Regantes) del departamento Pocito, compuesta mayormente de pequeños productores tecnificados que comparten el canal Calle 9, con un área concesionada de 741 ha y una importante diversidad de cultivos. Con ayuda de un SIG como soporte, se ha realizado un relevamiento de las Unidades Productivas y contrastado las demandas hídricas de los cultivos con el suministro de la red de riego colectiva, asociando los resultados del Balance Hídrico con las estrategias de riego tanto a nivel parcelario (individuales) como colectivo. De éste primer análisis de la gestión del agua para riego como Recurso de Uso Común (RUC) se perfilan una serie de escenarios de modernización compatibles con prácticas ya instituidas por los regantes.
\end{abstract}

Palabras claves: modernización, regantes, San Juan, Argentina, organización, RUC

\begin{abstract}
Analyzing modernization of traditional irrigated areas in western Argentina. The Tulum Valley, in San Juan, is one of the largest traditional irrigated areas in western Argentina. Of pre-hispanic origin in the XII century this oasis holds a population of some 600,000 people, concentrating $90 \%$ of the province's total. Its 120,000 ha of irrigation concessions have shaped a complex agro-ecosystem where irrigation still accounts for more than $90 \%$ of water allocations based on seniority rights; inherent to the land, irrevocable and perpetually granted. In this conservative context, modernization of irrigation have been focused either at large hydraulic infrastructure, i.e. dams and main canals, in one end, or at farm level, in the other. For several reasons, Collective Action for communal management of water has become marginal and both institutional and technological changes have lagged behind. Under this situation, this work studies one administration unit (Irrigation Commission) in the Pocito County made up mainly of small and diversified progressive farmers who share the Calle 9 canal that irrigates 741 ha. With a GIS as a support tool, all Productive Units have been surveyed and crop's water needs contrasted to water supply by the irrigation network, relating water balance to irrigation strategies at both farm and collective level. This first analysis of water management as a Common Pool Resource (CPR) gives insight to modernization scenarios compatible with already institutionalized practices.
\end{abstract}

Keywords: modernization, irrigators, San Juan, Argentina, organization, CPR

"La meta es generar un Plan Nacional de Riego que proponga duplicar la superficie regada de nuestro país pensando en objetivos productivos de cara al 2030"

Carlos Casamiquela, Ministro de Agricultura, Ganadería y Pesca de la Nación. 13 de marzo de 2014. Viedma, provincia de Río Negro.

\section{Introducción}

La FAO, en 1997, definía la modernización de regadíos como "un proceso de mejora técnica y de la gestión de los sistemas de riego, acompañada de reformas institucionales en caso necesario, con el objetivo de mejorar la utilización de los recursos y el servicio de sumi- 
nistro de agua a las explotaciones" (FAO, 1997). En este trabajo adherimos a esa definición respecto a los objetivos de la modernización, es decir, la mejora en la utilización de los recursos y el servicio de suministro de agua. Sin embargo, en cuanto a los componentes a evaluar en el proceso de modernización, nuestro enfoque pone al diseño institucional por delante, como los caballos que tiran de un carro. En ese sentido, la mirada se asimila más a la de Elinor Ostrom y otros autores neo-institucionalistas que en las últimas décadas han realizado un importante aporte a la administración de los llamados Recursos de Uso Común (RUC), y en particular al agua y los sistemas de riego (Miranda, 2011, 2011a y 2012).

No es nuestra intención detenernos aquí a analizar del enfoque institucional de Ostrom $(1990,1993)$. Muchos trabajos lo han hecho, incluidos los citados en el párrafo anterior, de nuestra autoría. Sólo acotaremos en este contexto que los RUC son definidos como bienes cuyo uso por una persona substrae del (o disminuye el) uso por otros y donde, por su propia naturaleza, es difícil excluir usuarios (actuales y potenciales). En otras palabras, son bienes que poseen alta rivalidad con baja "excludibilidad", por lo tanto su uso debe ser necesariamente compartido entre usuarios. También Ostrom entiende por institución al conjunto de normas "de uso" que rigen un RUC, siendo de conocimiento común, supervisadas y cumplidas. El concepto va más allá de la existencia de una organización formal, en el sentido de una figura jurídica determinada, y dichas normas, para ser efectivas, deben ser percibidas y aceptadas por los usuarios. De manera más llana, institución son las reglas del juego mientras que organización son los jugadores (Miranda, 2011, 2011a y 2012).

Siendo la modernización un proceso, donde no hay principio ni final, la provincia de San Juan, y en especial el Valle de Tulum, ofrece una situación empírica ideal para el estudio de su instrumentación. Constituye uno de los mayores regadíos tradicionales del oeste argentino. De origen prehispánico en el siglo XII este oasis actualmente alberga una población de unos 600.000 habitantes, concentrando el $90 \%$ del total provincial. Sus 120.000 ha de concesiones de riego agrícola conforman un complejo agro-ecosistema donde los regantes aún se llevan más del $90 \%$ de las asignaciones de agua y cuentan con derechos fuertemente consolidados; inseparables de la propiedad de la tierra, irrevocables y a perpetuidad. Además, aunque el sistema se encuentra consolidado en sus infraestructuras, en las últimas décadas las mejoras se han centrado a nivel de grandes obras hidráulicas, en un extremo, y parcelario, en el otro, quedando como asignatura pendiente los niveles medios, justamente los más complejos desde el punto de vista de la Acción Colectiva.

En este sentido nos proponemos evaluar el desarrollo de un proceso de modernización en un área piloto del departamento de Pocito, San Juan, compatible con las limitaciones y potencialidades del contexto institucional existente.

\section{La Autoridad de Aguas}

La Autoridad de Aguas en San Juan se llama Departamento de Hidráulica (DH), creado por la Ley 886 de 1942. Es una institución de Derecho Público de carácter autárquico, perteneciente al Ministerio de Infraestructura y Tecnología de la provincia, que tiene a su cargo el gobierno, administración y policía de las aguas en todo el territorio de la provincia. Al ser en la República Argentina los Recursos Naturales, incluidas las aguas, de dominio provincial, y más allá de los conflictos interjurisdiccionales entre provincias que se puedan suscitar, el DH es la única autoridad de aguas en San Juan.

El DH tiene varios Órganos de Gobierno. Para simplificar, diremos que cuenta, por un lado, con un órgano ejecutivo, que responde al Estado provincial, y por el otro, con tres niveles de órganos consultivos de carácter vinculante, con participación de los regantes. La 
Dirección General y sus Delegaciones en cada Término Municipal son el brazo ejecutivo del DH. Entre los órganos consultivos destaca el Honorable Consejo (HC), formado por tres representantes del Estado y tres regantes electos. Además, coincidiendo con la jurisdicción de cada Delegación existen las Juntas Departamentales (JD), formadas por tres regantes electos, y a nivel de canales, las Comisiones de Regantes (CR), formadas también por tres regantes electos. A fines prácticos, y para que se entienda cual es el rol de los regantes en la provincia y el área de estudio de este trabajo, vale decir, que los regantes son parte de la administración del agua con capacidades limitadas de gestión, entendiéndose a la gestión como la parte ejecutiva de administración, orientada a los logros (Gonzalez Aubone, 2013).

Tabla 1: La administración del riego en San Juan. Planos administrativos y fisicos

\begin{tabular}{|c|c|c|c|}
\hline \multicolumn{2}{|c|}{ ADMINISTRATIVO } & \multicolumn{2}{c|}{ FÍSICO } \\
\hline ESTADO & USUARIOS & ÁREAS & CANALES \\
\hline $\begin{array}{c}\text { D. GENERAL / } \\
\text { CONSEJO }\end{array}$ & CONSEJO & $\begin{array}{c}\text { ZONAS (3 zonas provin- } \\
\text { ciales) }\end{array}$ & CANALES MATRICES \\
\hline DELEGACIÓN & JD & $\begin{array}{c}\text { DEPARTAMENTO } \\
\text { (T. Municipal) }\end{array}$ & CANALES \\
\hline DELEGACIÓN & JD & SECCIÓN & CANALES \\
\hline DELEGACIÓN & CR & DISTRITO & $\begin{array}{c}\text { RAMO / CANAL } \\
\text { TERCIARO }\end{array}$ \\
\hline \multicolumn{2}{|c|}{ REGANTES COMUNEROS } & FINCAS/CULTIVOS & $\begin{array}{c}\text { ACEQUIA / RAMOS } \\
\text { COMUNEROS }\end{array}$ \\
\hline
\end{tabular}

Fuente: Elaboración propia

\section{3 Área de Trabajo}

Dentro del Valle de Tulum, se ha elegido como área de trabajo un distrito que cuenta con 741 ha de concesiones de agua para riego, ubicado en el Departamento Pocito, unos $15 \mathrm{~km}$ al sur de la ciudad de San Juan, capital de la provincia. Este distrito se corresponde con una CR formada por tres miembros electos de manera directa, cada uno representando los tramos superior, medio e inferior del canal Calle 9 del que se sirven. Este canal tiene la ventaja de tomar el agua directamente de uno de los tres canales matrices del valle, el Canal Céspedes, y estar impermeabilizado en hormigón en los $7 \mathrm{~km}$ de su recorrido, de Oeste a Este, con una pendiente regular del $0,8 \%$.

La normativa da a este tipo de canales el rango genérico de Terciarios y comúnmente la gente se refiere a ellos simplemente como "Ramos". Es decir, que este canal cuenta para su administración con una CR (también llamada Comisión de Canal). Los ramos/canales a cargo de un CR son la última unidad administrativa del DH. Sin embargo, éstos aún derivan agua a las acequias llamadas Ramos Comuneros ( $\mathrm{RC}$ ), que son las que reparten el agua a las fincas o usuarios finales. Estos RC son, tanto organizativamente como de propiedad, privados, es decir, que pertenecen a los regantes que los usan, aunque el DH ejerce el poder de policía y debe garantizar las servidumbres de paso de los mismos. 


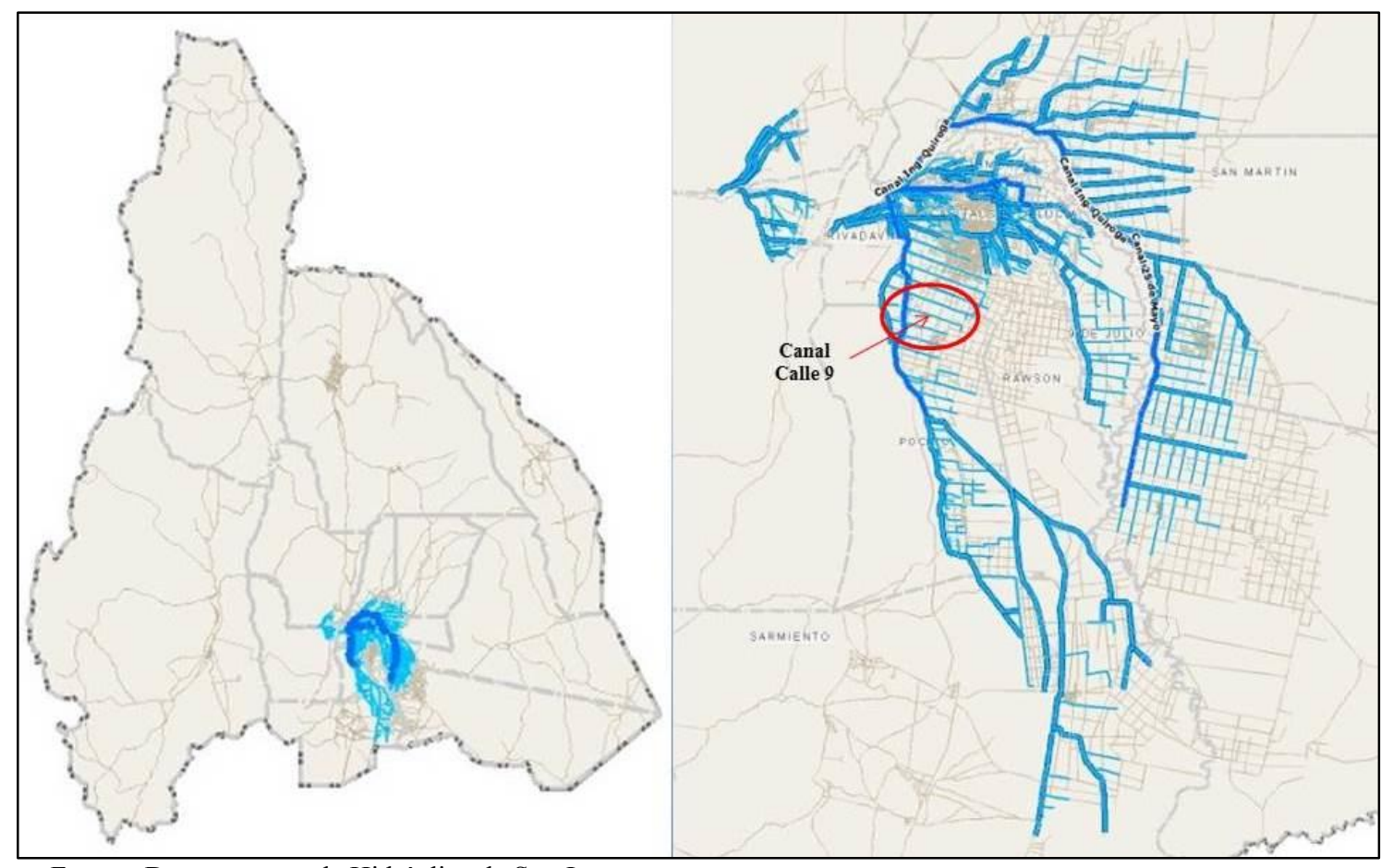

Fuente: Departamento de Hidráulica de San Juan

Fig. 1. San Juan y la red de riego del Valle del Tulum

\section{La Ley de Aguas}

La ley de Aguas en San Juan es el Código de Aguas (CA), ley 4932 de 1978, que rige el sistema de aprovechamiento, conservación y preservación de los recursos hídricos pertenecientes al dominio público. Este código incorpora la ley 886 de creación del $\mathrm{DH}$, como libro cuarto, bajo el título de "Gobierno y Administración de las Aguas". Cualquier análisis del desempeño actual del regadío en San Juan y de las posibles actuaciones de modernización que surjan de este u otro trabajo deberán hacerse bajo la lupa de esta normativa, elemento fundamental, aunque no exclusivo, de la institucionalidad del riego en San Juan. Como se ha definido a las instituciones como las "reglas de juego", sean éstas escritas o de facto, en la siguiente sección analizaremos el régimen de concesiones, distribución y uso del agua para riego teniendo en cuenta ambos aspectos, ya que las prácticas instituidas y aceptadas no pocas veces se desvían o hasta contradicen la norma escrita. De aquí en adelante, nos referiremos a todas estas cuestiones de manera genérica como el "diseño institucional" en el que se enmarca el área de trabajo, sea el actual o el deseado a la hora de plantear una modernización.

\section{El diseño institucional}

Este diseño obviamente no puede reemplazar al diseño físico de un sistema de riego o regadío ni aumentar los recursos hídricos disponibles en las fuentes. El enfoque de Ostrom, sin embargo, al plantear las instituciones como las reglas del juego, asume sí que este diseño tiene una influencia, deseada o indeseada, sobre el desempeño general y sus impacto. 


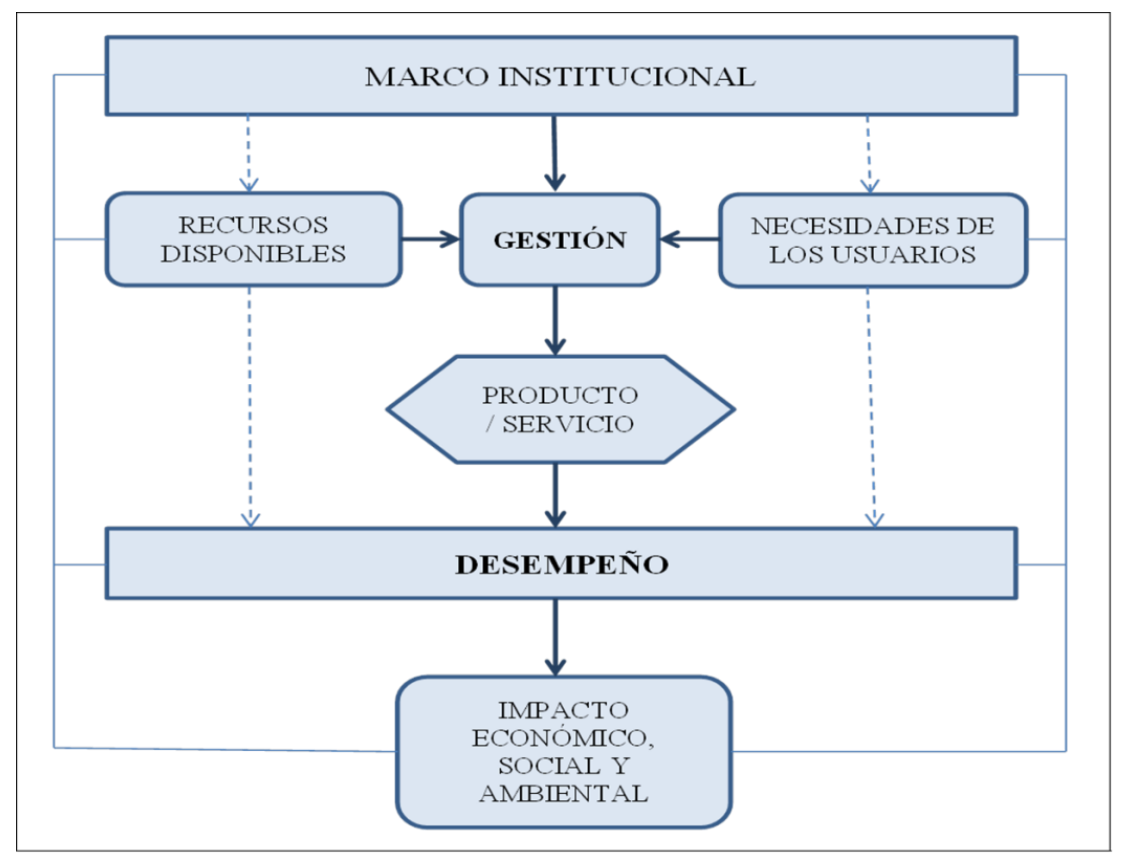

Fuente: Elaboración propia

Figura 2: Esquema de impacto institucional

a) Régimen concesional

El CA de 1978 establece un régimen único concesional en relación a sus aspectos más relevantes de cara a una modernización de regadíos. El Art. 121 dice que "todas las concesiones (...) cualquiera sea su origen, denominación, cauce o fuente proveedora, serán en adelante permanentes y se regirán por un régimen único e igual en todos los aspectos legales, incluidos coeficientes".

b) El principio de inherencia

La RAE define inherencia como la "unión de cosas inseparables por su naturaleza, o que solo se pueden separar mentalmente y por abstracción". Este principio al que adhieren muchas normativas hídricas implica una adscripción del agua con la tierra, con la finalidad de brindar una garantía y/o seguridad jurídica a una riqueza incorporada o a incorporarse al patrimonio de un predio (Pinto, 2004). En otras palabras, sobre todo en zonas áridas y semiáridas, es el agua el que le da valor a los terrenos de cultivo, y ese valor debe permanecer unido.

Las concesiones de riego en San Juan están basadas en este principio, consagrado en su Constitución. El Art. 117 dice que "La concesión de uso y goce del agua para beneficio y cultivo de un predio, constituye un derecho inherente e inseparable del inmueble y pasa a los adquirientes del dominio, ya sea a titulo universal o singular". A su vez el CA complementa su aplicación, siendo de especial interés para este trabajo también su Art. 117 que expresa que "la concesión para uso agrícola no da a su titular ningún derecho de dominio sobre el agua pública, sino que crea a su favor un derecho patrimonial subjetivo, de uso excluyente, para el riego de su propiedad".

La rigurosidad del principio establece que ni una gota de agua asignada a una finca puede ser usada por otra, aunque sea del mismo propietario o rieguen por el mismo canal. Así, dadas una oferta o suministro de agua, las opciones del regante se reducen a regar, almacenar o tirar el agua al desagüe, sin poder ajustar el riego a la demanda de los cultivos. 
No debe sorprender, por tanto, que la inherencia se practique en versión flexible y que existan las reasignaciones entre usuarios, muchas veces, inclusive, con la anuencia y colaboración del DH. En el caso de la provincia de Mendoza, por ejemplo, el propio Departamento General de Irrigación (Autoridad de Aguas) dice en su sitio web respecto a la inherencia: "no obstante la rigidez del principio, actualmente se tiende a flexibilizarlo analizando cada caso en particular".

Así y todo, debemos concluir que la inherencia, a menos que se reglamente su flexibilización, como en parte lo ha hecho España con el Art. 67 de su Ley de Aguas que permite la cesión de derechos de manera temporal, se contrapone con una gestión del riego a la demanda, sea para una planificación anual o interanual. De ahí la innumerable cantidad de mecanismos "cuasi" formales e informales que se han desarrollado para reasignar agua entre regantes.

c) La dotación

El Art. 51 del CA dice que "la medida, extensión o magnitud de la concesión se determinará en hectáreas, traducidas a litros por segundo". Algunos artículos complementan esto:

El Art. 125 dice que "dan derecho a la utilización de una dotación con un coeficiente uniforme de basta 1,30 l/s.ha", el Art. 126 que "la igualdad legal del coeficiente único será la establecida mediante aforos en el comparto en que comienza la acequia para la propiedad respectiva", y el Art. 127 que "queda expresamente prohibido disponer coeficientes diferenciales, so pretexto de diversidad de características de tierras y/ o cultivos".

En resumen, las dotaciones en San Juan se rigen por caudal aforado (expresado como coeficiente) en las compuertas que dan origen a los $\mathrm{RC}$, sin comprometer, en ningún caso, un volumen anualizado. El término volumen, sin embargo, es a veces mencionado en el CA pero sobre todo se encuentra implícito todos los años en octubre cuando el $\mathrm{DH}$ publica su pronóstico de derrame del Río San Juan, el estado de los embalses y acuíferos, etc. Aunque la normativa no prevé una planificación hidrológica formal, los regantes saben de antemano, la riqueza o pobreza hídrica del año y de alguna manera ajustan sus cultivos en función de esto. El punto más crítico de este sistema de dotación es la prohibición de entregas diferenciales por tipo de suelo y/o cultivo. Esto, sumado a la inherencia, atenta contra principios básicos de la eficiencia, no sólo desde el punto de vista físico sino económico y agronómico.

\section{d) El uso conjunto}

Este término hace referencia a la unicidad del recurso hídrico, sea extraído de fuentes superficiales o subterráneas. El Art. 128 del CA se refiere a éste diciendo que "el DH (...) dispondrá reforzar las dotaciones para completar los volumenes que correspondan, sin discriminar los orígenes de los refuerzos, haciendo un uso conjunto del recurso bídrico común”. Otros artículos complementan este uso:

El Art. 154 dice que "los sobrantes y excedentes, y toda otra agua que corra por los desagües, pertenece al dominio público y será afectada a la atención de las obligaciones emergentes de las concesiones" y el Art. 188que "la totalidad de las perforaciones que realice el estado para uso agrícola en acuiferos y subálveo vinculados al área de riego (...) sólo podrá ser empleado para reforzar las dotaciones correspondientes a las concesiones ya otorgadas, en uso conjunto".

El Uso Conjunto hace posible no solamente el reuso de los excedentes, vertiéndolos nuevamente a la red de riego y atendiendo las concesiones aguas abajo, sino el uso de las aguas

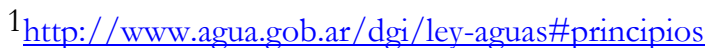


subterráneas como si de un embalse se tratase. Permite suplementar y reforzar dotaciones tanto en años hidrológicamente pobres como en zonas donde la red de riego no puede abastecer el sistema en tiempo y forma. Las aguas subterráneas fueron muy usadas en los 70 del siglo pasado, cuando el Río San Juan no contaba con embalses de regulación, llegando a funcionar más de 200 perforaciones estatales que bombeaban a los canales. Actualmente, a pesar de llevar cuatro años continuados de sequía, el costo de bombeo y quienes lo asumen, ha limitado enormemente este uso, de gran utilidad estratégica para una modernización de regadíos.

e) La distribución

Terminaremos este análisis institucional con la forma en la que se distribuye al agua. En este sentido, se debe distinguir entre la distribución en canales y ramos y la realizada en RC / acequias, de acuerdo al esquema presentado en la Tabla 1.

A nivel de canales y ramos, el Art. 160 del CA establece que "la distribución del agua se hará por turnos en tiempos de escasezy cuando resulte técnicamente inconveniente que el agua se distribuya continuamente". Esto se traduce en que la modalidad más usada y preferida consiste en operar la red "a canal mojado". Aunque algunas CRacuerdan poner sus canales a turno, no es el caso de Pocito, donde abundan los cultivos hortícolas y suelos son poco profundos y permeables. En este caso, cuando el sistema general está operando, el canal Calle 9 está transporta y distribuye agua a los RC.

El caudal distribuido en cada momento va en función de la dotación (superficie concesionada) y el coeficiente de distribución. A lo largo del año la dotación es constante, por lo que la cantidad suministrada se ajusta a través de un coeficiente, que debe ser "único e igual" para una misma fecha y para todos los canales del sistema. Así, por ejemplo, el día 25 de noviembre de 2011, desde Distribución Matriz se derivaba, de manera subsecuente:

Tabla 2: Distribución por Dotación y Coeficiente

\begin{tabular}{|l|c|c|c|}
\hline & Caudal (m³/s) & Dotación (ha) & Coef. (I/s.ha) \\
\hline Valle del Tulum & 48,254 & 118.952 & 0,406 \\
\hline Canal Céspedes & 18,065 & 44.372 & 0,406 \\
\hline Canal Calle 9 & 0,302 & 743 & 0,406 \\
\hline
\end{tabular}

Fuente: Elaboración propia con datos del Departamento de Hidráulica de San Juan

Por tanto, el sistema aplicado es muy sencillo y se basa mayormente en modificar el caudal a lo largo de la temporada y en función de las disponibilidades anuales, expresado en forma de coeficiente. Un coeficiente de 0,4 significa $0,4 \mathrm{l} / \mathrm{s}$.ha de dotación en un momento determinado. Como veremos más adelante, la curva de distribución anual acompaña tanto la disponibilidad natural dada por los caudales del río y la demanda del cultivo principal en el Valle del Tulum, la vid².

A nivel de Ramos Comuneros, la distribución se hace por turnos entre regantes según una Orden de Turnado por la cual los comuneros acuerdan el Intervalo Administrativo. Éste establece los días entre un turno y el siguiente, es decir cada cuanto tiempo cada regante va a recibir el agua. En el área de trabajo la mayoría de RC manejan intervalos de 72 o 78 horas. Este último formato es para evitar que el mismo regante tenga el agua siempre a la misma hora e ir rotando los turnos nocturnos.

${ }^{2}$ El régimen del Río San Juan es de tipo nival. Las precipitaciones se acumulan en forma de nieve en la Cordillera del Andes y el derrame aumenta junto con las temperaturas estivales. 
El caudal de entrada al RC sigue la fórmula Dotación (ha) x Coeficiente (l/s) y los turnos entre comuneros duran en función del área concesionada de cada una.

Tabla 3: Orden de turnado en ramo comunero

\begin{tabular}{|c|c|c|c|c|c|}
\hline $\begin{array}{l}\text { COMPUERTA: } \\
\text { DOTACIÓN: } \\
\text { INTERVALO: }\end{array}$ & $\begin{array}{l}09200302 \\
52,16 \\
78\end{array}$ & $\begin{array}{l}\text { ha } \\
\text { hs }\end{array}$ & $\begin{array}{l}\text { TURNADO: } \\
\text { NETO: }\end{array}$ & $\begin{array}{l}1,50 \\
1: 29: 43 \\
74 \text { hs. } 240\end{array}$ & $\begin{array}{l}\text { hs/ha } \\
\text { hs/ha }\end{array}$ \\
\hline ORDEN DE RIEGO & CONCESIONARIO & $\begin{array}{c}N^{\circ} \text { DE } \\
\text { CUENTA }\end{array}$ & NC & $\begin{array}{c}\text { DOTACIÓN } \\
\text { HAS }\end{array}$ & $\begin{array}{c}\text { TIEMPO QUE } \\
\text { CORRESPONDE }\end{array}$ \\
\hline 1 & ACOSTA ROMERO, MIGUEL Y OTRA & 805 & $0534 / 560620$ & 4,3229 & $06: 27: 50$ \\
\hline 2 & GOMEZ, LORENZO & 844 & $0534 / 550640$ & 4,3229 & $06: 27: 50$ \\
\hline 3 & RUIZ ROMERO, FERNANDO Y OTRO & 806 & $0534 / 540670$ & 8,6804 & $12: 58: 47$ \\
\hline 4 & MUÑOZ, ANTONIO Y OTRO & 807 & $0534 / 480640$ & 8,7478 & 13:04:49 \\
\hline 5 & GARCIA, JUAN & 810 & $0534 / 440630$ & 8,2480 & 12:19:59 \\
\hline 6 & MANRIQUE E, ANTONIO J Y JUAN & 811 & $0534 / 400600$ & 8,4488 & 12:38:00 \\
\hline 7 & COBOS FERNANDEZ, JUAN & 812 & $0534 / 350570$ & 0,3934 & $00: 35: 18$ \\
\hline 8 & MANRIQUE JUAN & 7349 & $0534 / 350600$ & 9,0000 & 13:27:27 \\
\hline CAMBIOS & & & & 52,1642 & 78:00:00 \\
\hline
\end{tabular}

Fuente: Departamento de Hidráulica de San Juan

Cada regante usa todo el caudal del RC durante el tiempo asignado, cumpliendo con el Art 162 del CA que dice que "en la distribución y reparto del agua todo criterio o norma reglamentaria que se adopte debe encuadrarse en la más estricta igualdad entre los regantes".

\section{Trabajo de campo}

El área de trabajo se definió conjuntamente con la Delegación Pocito del DH y se consensuó con la CR del canal Calle 9. En todo momento se ha contado con la colaboración del Inspector Técnico, el tomero (celador) a cargo de las compuertas y los regantes. Para el desarrollo del estudio se utilizaron las siguientes fuentes de información:

a) Clima

Para las condiciones climáticas se contó con datos de la Estación Agro-meteorológica EEA INTA Pocito, ubicada sólo a $2 \mathrm{~km}$ del área de estudio. Los datos disponibles corresponden a la serie 1969-2013, que se publica en el Boletín Agro-meteorológico de la página web del INTA EEA San Juan.

\section{b) Concesiones}

La delegación del DH proporcionó las planillas con las concesiones de riego del canal y todos sus datos, incluidos las órdenes de turnado y los intervalos administrativos como los mostrados en la Tabla 3 más arriba.

c) Catastro parcelario

También se contó con el Catastro Provincial en formato "shapefile".

d) Cultivos

La información de cultivos para el año 2013 se obtuvo mediante relevamiento de campo in situ acompañado de fichas completadas conjuntamente con los regantes.

e) Necesidades hídricas de los cultivos 
Para el cálculo de los necesidades de riego de los cultivos se tuvieron en cuenta los trabajos desarrollados por el INTA EEA San Juan (Liotta, 2010 y 2011). Estos consideran las demandas especiales como lavado de sales, riegos de pre y post siembra, etc.

f) Suministro de agua

Estos se obtuvieron de los registros diarios que publica el DH sobre dotaciones y coeficientes de entrega. Se tomó el ciclo que va desde julio de 2012 a junio de $2013^{3}$.

g) Unidades productivas

Uno de los desafíos ha sido adecuar la situación real de tenencia y explotación de la tierra respecto a la informada tanto en los padrones catastrales de la provincia de San Juan como del DH. Las concesiones de riego figuran en la escritura de la propiedad y los cambios de explotación (uso, compra, venta, división, concentración, etc.) y su reflejo en los padrones oficiales demoran a veces varios años entre que se producen y se formalizan registralmente. Por ese motivo el primer paso en este trabajo ha sido identificar, mediante relevamiento de campo, las Unidades Productivas (UP), es decir aquellas tierras que se administran y cultivan de manera unificada y son regadas dentro de un mismo RC.

h) Relación entre suministro y necesidades

Una vez determinada la demanda o necesidades de riego y calculada la oferta hídrica superficial a lo largo del calendario agrícola delaño hidrológico 2012 y 2013, se confrontaron ambas y se obtuvieron los déficits o excesos hídricos que permiten conocer estos balances.

\section{i) Eficiencias / Pérdidas}

El estudio no ha medido o estimado eficiencias o pérdidas en conducción y aplicación en esta etapa. Nuestro interés actual es conocer y entender en detalle el esquema de distribución y sus implicancias. Ver mayor detalle en la sección de Balances Hídricos.

\subsection{E1 Distrito Canal Calle 9}

Se localiza a los $31^{\circ} 37^{\prime}$ de latitud sur y $68^{\circ} 32^{\prime}$ de longitud oeste, a una altitud promedio de $618 \mathrm{msnm}$, en la zona de contacto entre el piedemonte precordillerano y la planicie aluvial. Los suelos predominantes son de textura franco limoso pertenecientes ala denominación local Complejo El Salado (CoEs), cuyo perfil se caracteriza por una textura variada apoyado sobre un subsuelo de gravas, gravillas o rodados. Son suelos generalmente de alta infiltración que requieren alta frecuencia de riego, sin problemas de niveles freáticos altos, siendo el acuífero confinado.

Se trata de una zona que tradicionalmente ha tenido un alto valor productivo debido a un clima suave que favorece las producciones tempranas de frutas y hortalizas para mercado en fresco. Presenta también buena aptitud para cultivos sensibles a las heladas tardías como el olivo y el almendro. A esa dinámica productiva se le ha sumado en las últimas dos décadas una nueva dinámica poblacional y urbanística debido a la belleza de sus paisajes y la proximidad con la ciudad de San Juan y su periferia. La puja entre lo rural y lo urbano, lo productivo y lo recreativo, actualmente plantean un gran desafío desde el ordenamiento territorial. El canal Calle 9 distribuye el agua en 16 compuertas a lo largo de su recorrido, cada uno dando inicio a un RC. La Figura 3 muestra el área de dominio de cada compuerta.

\footnotetext{
3 Junio y julio son los meses de invierno donde se entrega menos caudal de agua y el sistema funciona menor número de días por limpieza y mantenimiento de la red de riego.
} 


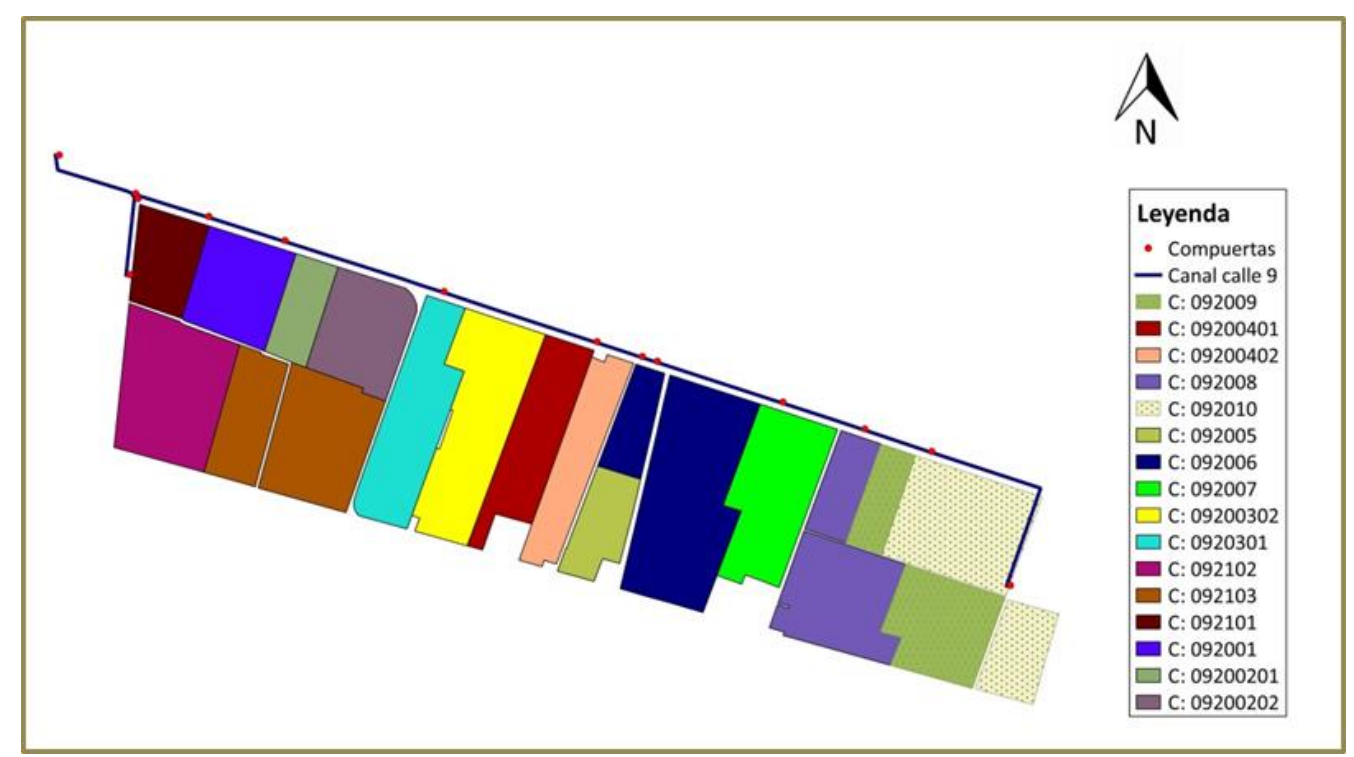

Fuente: Elaboración Propia

Fig. 3: Distribución de área regable por Compuerta (Ramo Comunero)

\begin{tabular}{|c|c|c|c|}
\hline \multirow{19}{*}{ Superficie cultivada (ha) } & & Superficie Cultivada Total & ha \\
\hline & & Olivo & 228 \\
\hline & & Tomate & 70 \\
\hline & m Olivo & Cebolla & 129 \\
\hline & - Tomate & Ajo & 108 \\
\hline & Cebolla & Vid & 51 \\
\hline & & Frutales & 15 \\
\hline & AjO & Melón & 4 \\
\hline & EVid & LechugaV & 34 \\
\hline & Erutales & Lechugal & 5 \\
\hline & Melón & Brocoli & 5 \\
\hline & E Lechuga V & Alfalfa & 2 \\
\hline & Jechugal & Zapallo & 6 \\
\hline & Lechuga I & Acelga & 4 \\
\hline & Brocoli & Poroto & 4 \\
\hline & \#Alfalfa & Pimiento & 3 \\
\hline & = Zapallo & Total: & 668 \\
\hline & Acelga & Concesionada: & 741 \\
\hline & & $\%$ Cultivada: & $90 \%$ \\
\hline
\end{tabular}

Fuente: Elaboración Propia

Figura 4: Distribución de cultivos y área concesionada total (ha)

En la campaña 2013/14 se cultivaron un total 668 ha, es decir un $90 \%$ de las 741 ha concesionadas, cifra muy superior a la media del Valle del Tulum, del 61\% según el último relevamiento del DH del año 2007 (DH, 2007). Los cultivos predominantes son el olivo, la vid, la cebolla, el ajo, el tomate, y la lechuga, mostrando la zona una alta diversidad productiva.

A nivel de cada compuerta/RC, la distribución por cultivos y escala de producción es la presentada en las tablas 4 y 5 . Cabe destacar la particularidad de la compuertas 2, 10 y 16, que sirven a sólo una UP, y entre éstas la compuerta 2, que monocultivo de olivo. 
Tabla 4: Perfil productivo por compuertas 1 a 8

\begin{tabular}{|c|c|c|c|c|c|c|c|c|c|}
\hline Cultivo & C1 & $\mathrm{C} 2$ & C3 & C4 & C5 & C6 & $\mathrm{C} 7$ & C8 & TOTAL \\
\hline Vid & & & & 8 & 5 & & 10 & 2 & 25 \\
\hline Frutales & & & 12 & & & & & & 12 \\
\hline Olivo & & 54 & 33 & 3 & & & 47 & & 137 \\
\hline Ajo & 4 & & & 3 & & 9 & & 9 & 24 \\
\hline Cebolla & 10 & & 4 & 14 & 1 & 58 & 2 & 7 & 95 \\
\hline Tomate & & & 11 & 5 & 8 & 2 & 9 & & 35 \\
\hline Melón & & & & & & 4 & & & 4 \\
\hline Lechuga (Verano) & 8 & & 3 & & 6 & & & & 17 \\
\hline Lechuga (Invierno) & & & 3 & & & & & & 3 \\
\hline Brocoli & & & & & 5 & & & & 5 \\
\hline Alfalfa & & & & & & & & & 0 \\
\hline Zapallo (calabaza) & & & & & 3 & & & & 3 \\
\hline Acelga & & & & & 2 & & & & 2 \\
\hline Poroto (alubia) & & & & & & 4 & & & 4 \\
\hline Pimiento & & & & & & & & & 0 \\
\hline TOTAL cultivado (ha) & 22 & 54 & 66 & 32 & 29 & 76 & 68 & 17 & 363 \\
\hline Dotación (ha) & 23 & 54 & 70 & 34 & 42 & 82 & 69 & 20 & 396 \\
\hline$\%$ de cultivo & $94 \%$ & $99 \%$ & $94 \%$ & $96 \%$ & $68 \%$ & $92 \%$ & $98 \%$ & $83 \%$ & $92 \%$ \\
\hline Unidades Productivas & 5 & 1 & 13 & 8 & 12 & 6 & 9 & 5 & 59 \\
\hline Sup media (ha) & 5 & 54 & 5 & 4 & 4 & 14 & 8 & 4 & 12 \\
\hline
\end{tabular}

Fuente: Elaboración Propia

Tabla 5: Perfil productivo por compuertas 9 a 16

\begin{tabular}{|c|c|c|c|c|c|c|c|c|c|}
\hline Cultivo & C9 & C10 & C11 & C12 & $\mathrm{C} 13$ & C14 & C15 & C16 & TOTAL \\
\hline Vid & & 9 & & 2 & 10 & 3 & & 4 & 27 \\
\hline Frutales & & & & 3 & & & & & 3 \\
\hline Olivo & 1 & 7 & 7 & 29 & 14 & & 28 & 7 & 91 \\
\hline Ajo & 26 & & 7 & 6 & 8 & 29 & 8 & & 84 \\
\hline Cebolla & 13 & 14 & & & 3 & & 2 & 3 & 34 \\
\hline Tomate & & 1 & 4 & & 19 & 7 & 6 & & 35 \\
\hline Melón & & & & & & & & & 0 \\
\hline Lechuga (Verano) & 11 & & 3 & & & 2 & 2 & & 17 \\
\hline Lechuga (Invierno) & & & & & & 2 & & & 2 \\
\hline Brocoli & & & & & & & & & 0 \\
\hline Alfalfa & & & 2 & & & & & & 2 \\
\hline Zapallo (calabaza) & & & & & 3 & & & & 3 \\
\hline Acelga & 2 & & & & & & & & 2 \\
\hline Poroto (alubia) & & & & & & & & & 0 \\
\hline Pimiento & & & & & 3 & & & & 3 \\
\hline TOTAL cultivado (ha) & 51 & 31 & 22 & 39 & 58 & 41 & 45 & 14 & 300 \\
\hline Dotación (ha) & 52 & 36 & 28 & 49 & 68 & 44 & 52 & 17 & 345 \\
\hline$\%$ de cultivo & $98 \%$ & $87 \%$ & $79 \%$ & $79 \%$ & $85 \%$ & $94 \%$ & $86 \%$ & $80 \%$ & $87 \%$ \\
\hline Unidades Productivas & 7 & 1 & 10 & 9 & 8 & 5 & 11 & 1 & 52 \\
\hline Sup media (ha) & 7 & 36 & 3 & 5 & 9 & 9 & 5 & 17 & 11 \\
\hline
\end{tabular}

Fuente: Elaboración Propia 


\subsection{Los balances hídricos}

Dados los perfiles productivos del distrito y sus subunidades, los balances hídricos son el indicador principal que analizamos en este trabajo. A continuación se presentan estos balances mensuales para cada compuerta y el general del canal Calle 9, considerando el suministro en cabecera, en azul, y la demanda de los cultivos, en rojo. Debido a la rigidez normativa del Principio de Inherencia y el Coeficiente Único que establece el CA, la curva de oferta de agua siempre tiene la misma forma, solamente variando la cantidad entregada en función de la superficie concesionada. Del lado de la demanda, el comportamiento de esta curva depende del área cultivada respecto a la concesionada, por un lado, pero fundamentalmente del tipo de cultivos predominante, sobre todo sin son de invierno (ajo, cebolla, lechuga) o de verano (olivo, vid, tomate).

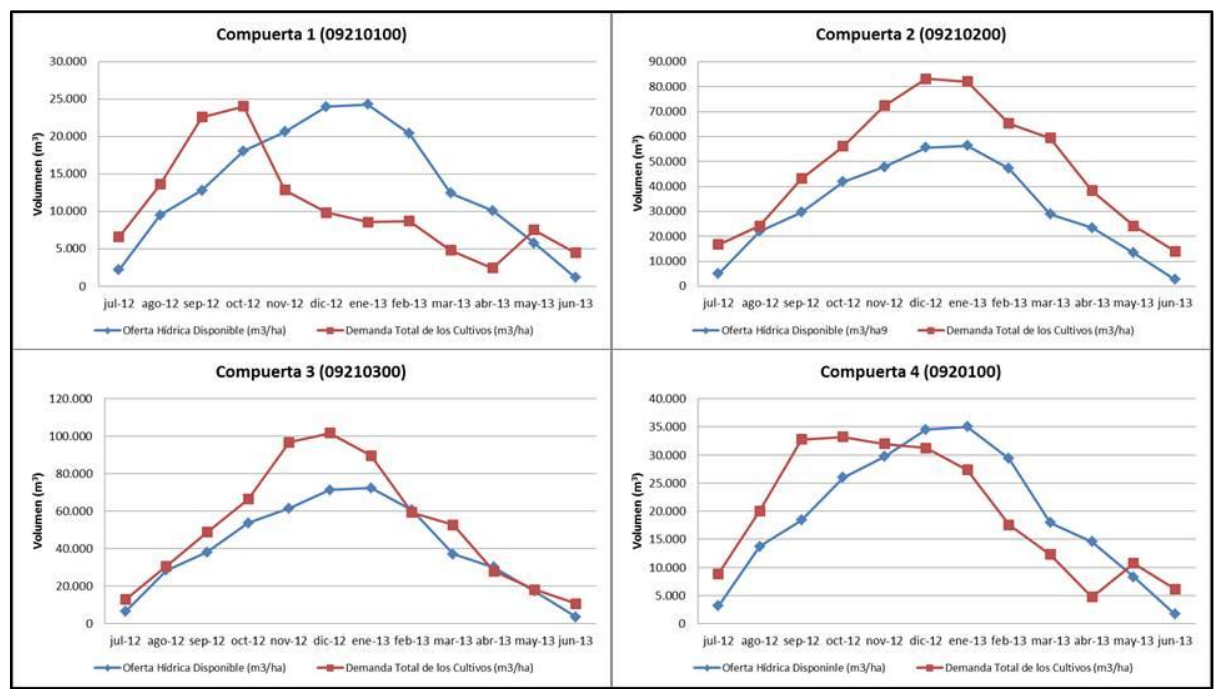

Fuente: Elaboración Propia

Fig.5. Balance hídrico compuertas 1 a $4\left(\mathrm{~m}^{3} / \mathrm{mes}\right)$

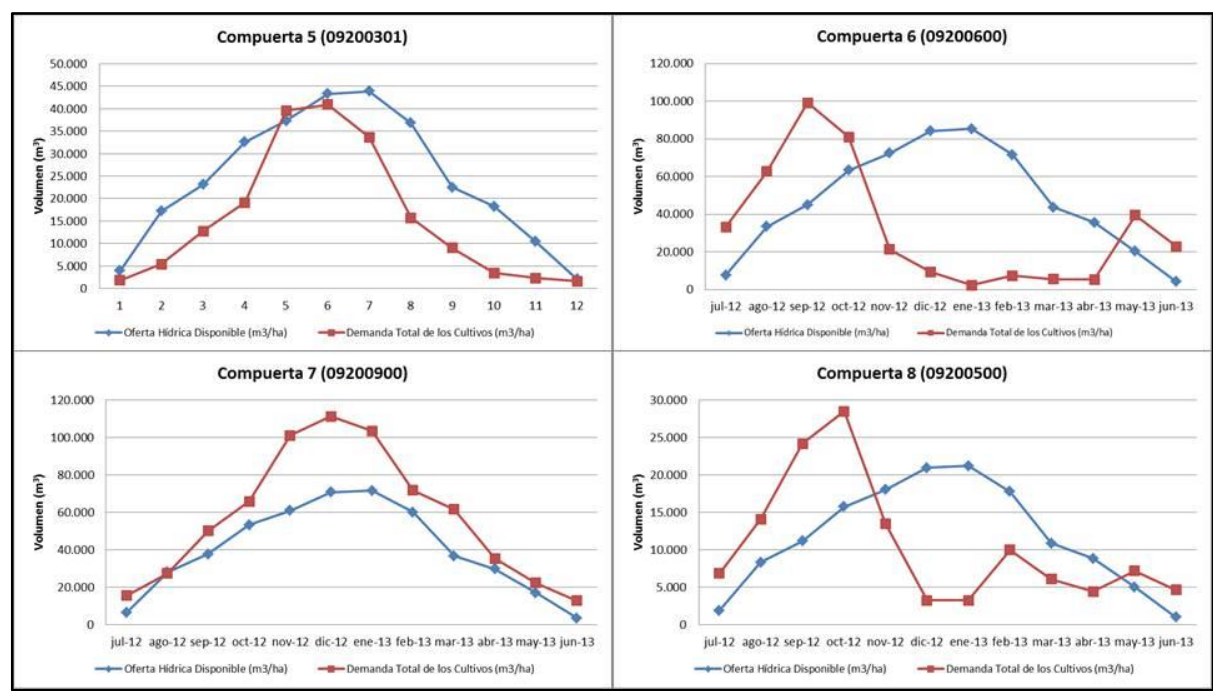

Fuente: Elaboración Propia

Fig. 6: Balance hídrico compuertas 5 a $8\left(\mathrm{~m}^{3} / \mathrm{mes}\right)$ 


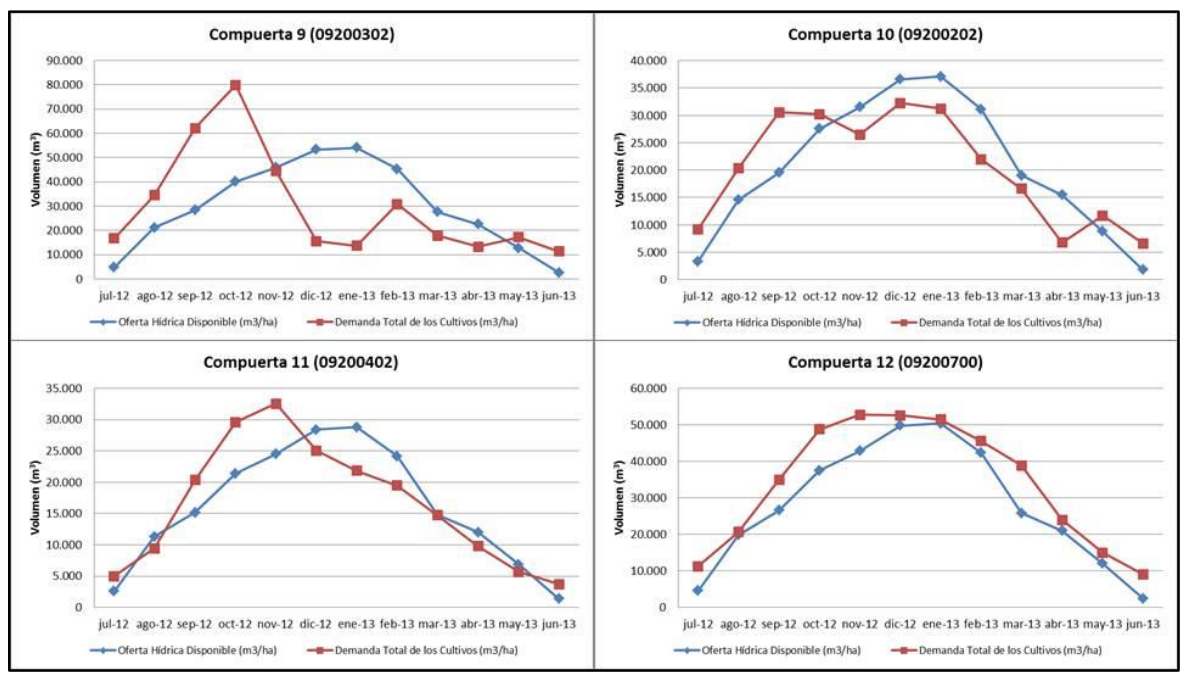

Fuente: Elaboración Propia

Fig. 7. Balance hídrico compuertas 9 a $12\left(\mathrm{~m}^{3} / \mathrm{mes}\right)$

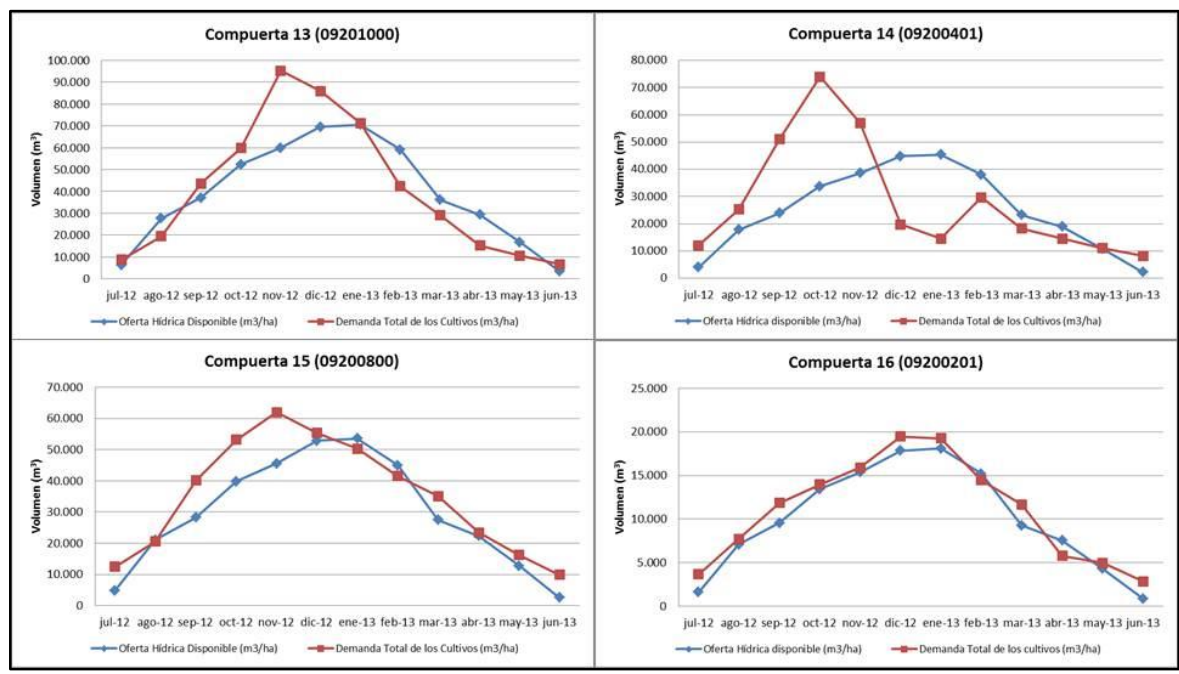

Fuente: Elaboración Propia

Fig. 8: Balance hídrico compuertas 13 a $16\left(\mathrm{~m}^{3} / \mathrm{mes}\right)$

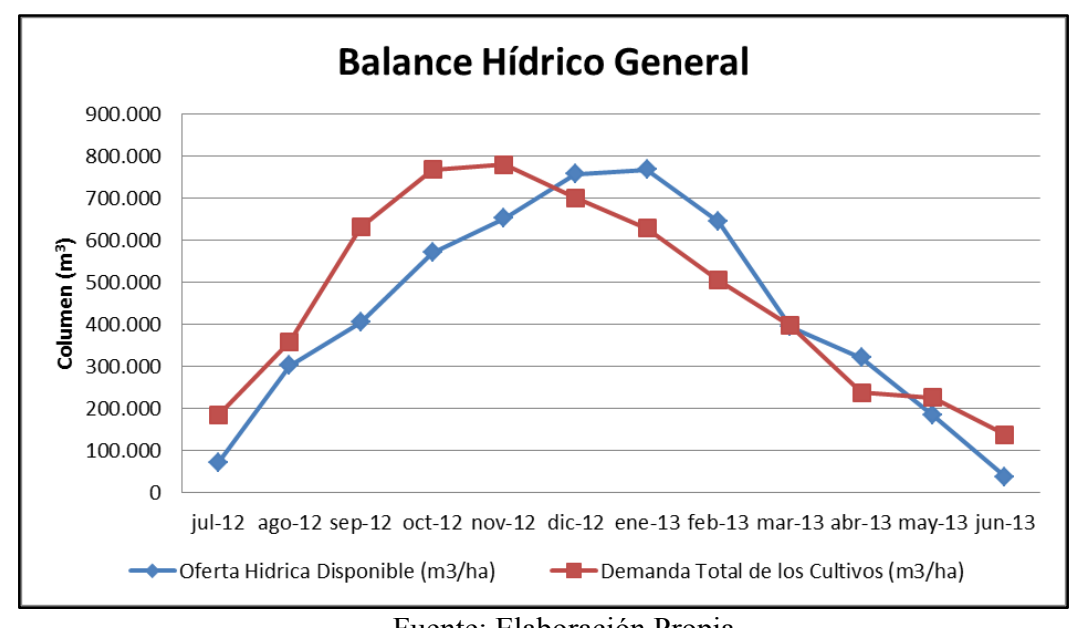

Fuente: Elaboración Propia

Fig. 9. Balance hídrico anual del Canal Calle 9 
Tabla 6: Balance bidrico anual del Canal Calle 9

\begin{tabular}{|c|c|c|c|c|c|c|c|c|c|c|c|c|c|c|}
\hline \multirow{2}{*}{ Total Canal Calle 9} & \multicolumn{2}{|c|}{ Dotación (ha): } & \multirow{2}{*}{$\frac{741}{\text { ago-12 }}$} & \multicolumn{2}{|c|}{ Cultivo (ha): } & \multirow{2}{*}{$\frac{668}{\text { nov-12 }}$} & \multirow{2}{*}{$\begin{array}{c}\%: \\
\text { dic-12 }\end{array}$} & $90 \%$ & \multirow[b]{2}{*}{ feb-13 } & \multirow[b]{2}{*}{ mar-13 } & \multirow[b]{2}{*}{ abr-13 } & \multirow[b]{2}{*}{ may-13 } & \multirow[b]{2}{*}{ jun-13 } & \multirow[b]{2}{*}{ Total } \\
\hline & & jul-12 & & sep-12 & oct-12 & & & ene-13 & & & & & & \\
\hline \multicolumn{15}{|l|}{ Entrega/Suministro } \\
\hline Días mes & & 31 & 31 & 30 & 31 & 30 & 31 & 31 & 28 & 31 & 30 & 31 & 30 & \\
\hline Días corta & & 25 & 10 & 2 & 0 & 0 & 3 & 3 & 0 & 8 & 10 & 11 & 23 & 95 \\
\hline Días distrib. & & 6 & 21 & 28 & 31 & 30 & 28 & 28 & 28 & 23 & 20 & 20 & 7 & 270 \\
\hline Dot (ha) & & 741 & 741 & 741 & 741 & 741 & 741 & 741 & 741 & 741 & 741 & 741 & 741 & \\
\hline Coef entrega & & 0,16 & 0,25 & 0,24 & 0,29 & 0,35 & 0,45 & 0,45 & 0,38 & 0,28 & 0,26 & 0,16 & 0,09 & \\
\hline Efici. Conduc. & & 0,95 & 0,95 & 0,95 & 0,95 & 0,95 & 0,95 & 0,95 & 0,95 & 0,95 & 0,95 & 0,95 & 0,95 & \\
\hline Vol. Cabecera (m3/ha) & & 98 & 428 & 575 & 811 & 927 & 1.077 & 1.091 & 915 & 559 & 455 & 259 & 52 & 7.247 \\
\hline Vol. Neto (m3/ha) & & 93 & 407 & 546 & 770 & 881 & 1.023 & 1.037 & 870 & 531 & 432 & 246 & 50 & 6.885 \\
\hline Vol. Compuerta (m3) & & 68.882 & 301.305 & 404.673 & 570.771 & 652.600 & 757.917 & 768.082 & 644.330 & 393.577 & 320.091 & 182.445 & 36.918 & 5.101 .589 \\
\hline Demanda Cultivo & SC (ha) & & & & & & & & & & & & & \\
\hline Olivo & 228 & 70.680 & 102.600 & 182.400 & 237.120 & 305.520 & 351.120 & 346.560 & 275.880 & 250.800 & 161.880 & 102.600 & 59.280 & 2.446 .440 \\
\hline Tomate & 70 & & & 37.100 & 44.800 & 169.400 & 133.700 & 81.200 & & & & & & 466.200 \\
\hline Cebolla & 129 & 64.500 & 122.550 & 184.470 & 129.000 & & & & & & & 78.690 & 43.860 & 623.070 \\
\hline Ajo & 108 & 43.200 & 87.480 & 169.560 & 247.320 & 132.840 & & & 92.880 & 55.080 & 49.680 & 38.880 & 29.160 & 946.080 \\
\hline Vid & 51 & & 21.930 & 24.990 & 46.920 & 83.130 & 110.670 & 110.160 & 76.500 & 50.490 & 10.200 & & & 534.990 \\
\hline Frutales & 15 & & 13.950 & 12.300 & 24.000 & 28.650 & 32.700 & 29.400 & 21.750 & 17.850 & 3.750 & & & 184.350 \\
\hline Melón & 4 & & & 1.600 & 2.360 & 6.000 & 5.560 & & & & & & & 15.520 \\
\hline Lechuga V & 34 & & 3.736 & 8.636 & 20.794 & 33.843 & 41.874 & 36.548 & 22.422 & 11.739 & 2.656 & & & 182.247 \\
\hline Lechuga I & 5 & 1.498 & 1.680 & 1.402 & 733 & & & & & 1.629 & 2.047 & 1.907 & 1.435 & 12.332 \\
\hline Brocoli & 5 & 1.498 & 1.680 & 1.402 & 733 & & & & & 1.629 & 2.047 & 1.907 & 1.435 & 12.332 \\
\hline Alfalfa & 2 & & 372 & 1.547 & 2.909 & 4.125 & 5.192 & 5.218 & 4.016 & 3.189 & 1.812 & & & 28.379 \\
\hline Zapallo & 6 & & & 2.993 & 6.344 & 9.285 & 11.160 & 11.029 & 6.613 & & & & & 47.424 \\
\hline Acelga & 4 & & 440 & 1.016 & 2.446 & 3.981 & 4.926 & 4.300 & 2.638 & 1.381 & 312 & & & 21.441 \\
\hline Poroto & 4 & 1.198 & 1.344 & 1.121 & 586 & & & & & 1.303 & 1.638 & 1.526 & 1.148 & 9.865 \\
\hline Pimiento & 3 & & 330 & 762 & 1.835 & 2.986 & 3.695 & 3.225 & 1.978 & 1.036 & 234 & & & 16.081 \\
\hline Vol. Demandado (m3) & 668 & 182.574 & 358.093 & 631.299 & 767.899 & 779.761 & 700.597 & 627.640 & 504.677 & 396.126 & 236.257 & 225.510 & 136.318 & 5.546 .751 \\
\hline Balance & & -113.692 & -56.788 & -226.626 & -197.129 & -127.160 & 57.320 & 140.442 & 139.652 & -2.549 & 83.834 & -43.066 & -99.400 & -445.162 \\
\hline
\end{tabular}

Fuente: Elaboración Propia

Cabe notar que estos balances hídricos son por compuerta y no por cada Unidad Productiva (propiedad), lo que simula los desfasajes de la demanda respecto a la oferta. Por esos motivos, este trabajo no considera las pérdidas ocurridas por conducción en RC y fincas ni las de aplicación, que dependen del método de riego. En ese sentido, adherimos a las observaciones de Charles Burt de que "las bajas eficiencias de riego a nivel de finca no están necesariamente vinculadas a las prácticas de aplicación. En muchos regadios son las autoridades de aguas las que determinan el programa y las cantidades de agua distribuidas y los agricultores casi no tienen opciones en este aspecto. Estas bajas eficiencias son generalmente indicadores de un sistema de distribución poco fiable, equitativo y flexible. Estos aspectos deberian ser mejorados antes que puedan tener lugar ganancias significativas en la eficiencia de uso a nivel de finca" (Burt, 2001). Estas pérdidas existen y pueden ser cuantiosas, pero su medición y/o estimación no aportarían mucho al objetivo de modernización del sistema, que principalmente replantea la distribución espacio-temporal del agua. Las eficiencias a lograr, en otras palabras, son consideradas una consecuencia de la modernización. Por eso hacemos hincapié en mostrar el desbalance temporal entre oferta y demanda, producto de un sistema conceptualmente rígido de distribución del agua, muy vinculado a su diseño institucional.

¿Cómo es posible que el área de estudio siga siendo altamente productiva a pesar del desfasaje de los balances hídricos y la presión inmobiliaria a la que está sometida en la actualidad? Evidentemente lo primero que tenemos que hacer es relativizar estos balances hídricos. Aunque la normativa legal proclame la inherencia y el coeficiente único, en términos 
filosóficos se llamaría a esto una entelequia. Sin embargo, tenemos que partir de ella en nuestro análisis. Por un lado, nos permite mostrar los contrastes entre lo institucionalizado y lo legal y, por otro señalar los posibles caminos a seguir de cara a una modernización que incluya los arreglos institucionales, como sostenemos que debería hacerse.

Las estrategias seguidas por los regantes incluyen acciones tanto individuales como colectivas. Ambas son fundamentales y se retroalimentan entre sí pero en el ámbito de este trabajo estamos más interesadas en las acciones colectivas. En ese sentido, podríamos asumir que colectivamente estamos ante la gestión de dos RUC; el agua y las infraestructuras comuneras (Bravo, 2008).

\subsection{Estrategias individuales}

Aunque la modernización del riego a nivel parcelario no forma parte de este estudio, al menos en esta primera etapa, cabe describir algunas acciones individuales que los regantes utilizan para una mejor gestión del agua para riego.

a) Perforaciones

El CA habilita al DH a otorgar permisos de perforación para uso de agua subterránea para riego. Dependiendo de la riqueza y calidad de los acuíferos, para los regantes que pueden pagarlas estas perforaciones constituyen una fuente adicional de agua "a la demanda"para reforzar la dotación superficial que distribuye la red de canales. Además del costo inicial de la perforación y el mantenimiento, normalmente se paga un costo fijo por la potencia instalada y un costo variable por la electricidad consumida. El DH no cobra canon o tasa alguna por su uso ${ }^{4}$.

\section{b) Reservorios}

Cada vez son más los regantes que construyen reservorios en sus predios para almacenamiento tanto de agua de turno como subterránea. Estos son más económicos cuando se cuenta con una perforación y/o los tiempos entre turnos son cortos; por un lado el pozo permite disminuir el volumen a almacenar y además el reservorio permite el bombeo en horarios de tarifa baja para su uso posterior.

c) Riego presurizado

Esta tecnología es cada vez más usada por los regantes del área de estudio. Individualmente debe aplicarse conjuntamente con reservorio y/o perforación, lo que encarece los costos de instalación y operación. Permite grandes ahorros de agua y aumentos de productividad en todo tipo de cultivos.

d) Impermeabilización de acequias internas

Reducen las pérdidas de conducción dentro de la finca.

e) Mangas, sifones, etc.

Mejoran la eficiencia de aplicación.

\footnotetext{
${ }^{4}$ Hay algunos temas controversiales sobre esto pero la norma instituida es básicamente esa.
} 


\subsection{Estrategias colectivas}

Acción colectiva es toda acción conjunta (involucra a más de una persona) que persigue unos intereses comunes y que para conseguirlos desarrolla unas prácticas de movilización concretas" (Funes Rivas, 2013). Sus postulados han sido ampliamente tratados por Elinor Ostrom respecto al gobierno de los RUC y en particular en el ámbito de la evolución institucional en regadíos tradicionales (Ostrom, 1990 y 1993).

Además de las acciones individuales a nivel predial para mejorar la gestión del agua yel desempeño de sus explotaciones agrícolas, los regantes dependen de un servicio de suministro del que forman parte constitutiva: el DH. Esta condición muchas veces los obliga a ser juez y parte e involucrarse en acciones colectivas tanto como usuarios así como administradores del recurso. Por otro lado, y siguiendo el concepto de las normas institucionalizadas como válido, nos encontramos con estrategias colectivas dentro los órganos formales de gobierno del agua, el Consejo, las JD y las CR, y otras más informales.

Diferentes trabajos, inclusive de nuestra autoría, han hecho hincapié en la escasa participación de los regantes en los citados órganos de gobierno (Miranda 2011, 2011a y 2012). Estos hacen referencia mayormente a la operación y mantenimiento de los canales. Sin embargo, a modo preliminar, este trabajo empieza a mostrar una fuerte acción colectiva muchas veces subrepticia, poco estudiada hasta ahora. Es muy lógico, ya que muchas son prácticas que contravienen el Principio de Inherencia y/o la entrega por Coeficiente Único. Esto últimos cuatro años, sin embargo, con la continuada sequía y consecuente menor disponibilidad de agua, éstas prácticas, a las que llamaremos reasignaciones, probablemente se hayan intensificado. De lo que sí estamos seguros es que tanto el DH como los regantes abordan el tema sin tapujos. Al momento de escribir estas líneas, desde nuestra ventana a la Calle 11 de Pocito, a dos calles del área de trabajo, puede verse el canal transportando y distribuyendo agua a los regantes con cultivos de invierno de la zona. Esto es producto de la creciente visibilidad de la acción colectiva mancomunada entre regantes y el DH para acordar reasignaciones y entregas diferenciales en función de la demanda de los cultivos. Estas prácticas asoman como positivas de cara a una modernización de regadíos.

\section{a) Reasignaciones administrativas}

Aunque la normativa prevé el corte del suministro a los morosos, ésta práctica se aplica poco, especialmente cuando la morosidad está vinculada al no uso temporal o prolongado del agua. Esta situación crea «bolsas» de horas de agua que pueden reasignarse en función de necesidades particulares, aumentando la eficiencia del sistema. Lo más común es que estas reasignaciones se hagan en $\mathrm{RC}$ aunque pueden verse también en canales.

Esto en el ámbito de un Distrito e inclusive Departamento. Pero además, todos los martes se reúnen los Inspectores Técnicos a cargo de las Delegaciones del DH con el Inspector General. Demandas de los regantes en mano, ahí ya es común verlos negociar coeficientes diferenciales por Canales Generales.

\section{b) Reasignaciones de mercado}

Sobre todo en tiempos de sequía como los actuales el agua se reasigna dentro de los RC siguiendo mecanismos de mercado. Son habituales los traspasos de horas de agua de una propiedad a otra, sea bajo una misma administración o entre regantes distintos.Estos traspasos funcionan tanto a manera de trueque por horas de agua en otro momento como por pagos en especie e inclusive en dinero. En el área de estudio, por ejemplo, hay un regante que cede todo el turno a su vecino ya que riega por goteo directamente desde una perforación. Como contraprestación, su vecino le paga la factura eléctrica del pozo. Se trata de 
pequeños mercados de agua que funcionan de manera eficiente y tienden a maximizar la productividad del agua dentro de estos pequeños distritos que son los RC.

c) Pozos comuneros

Algunos regantes comparten el uso de una perforación. Estas pueden ser de propiedad común, sobre todo en caso de subdivisiones por sucesión hereditaria, o individual. En todo caso se acuerdan normas de uso, mantenimiento y hasta de administración. Muchas veces se usan acequias internas o tuberías privadas para el transporte del agua desde una propiedad a la otra pero hay casos más complejos donde se hacen acuerdos de este tipo usando canales o RC para el transporte, siempre que tengan el consenso de los regantes que no participan del acuerdo.

\section{Discusión de los resultados}

Volviendo a la introducción donde decíamos que la modernización es un proceso sin principio ni fin, cabe mencionar que ésta a veces se materializa a saltos, es decir, mediante proyectos o planes regionales e inclusive nacionales, dadas unas condiciones favorables. Argentina parece estar en ese camino. Las palabras del Ministro de Agricultura no hacen más que apuntar a las metas productivas comprometidas en el Plan Estratégico Agroalimentario 2020 (PEA2) elaborado por su ministerio en 2011. En ese sentido, el trabajo que presentamos aquí recién comienza.

Los balances hídricos presentados indican que ningún proyecto de modernización podría pasar de pies juntillas sobre dos elementos normativos que, con la ley en la mano, van en contra del suministro de agua para riego en función de la demanda de los cultivos que maximizan la rentabilidad del productor: el Principio de Inherencia y la entrega por Coeficiente Único. Estos dos elementos dictan una asignación completamente rígida, que tal vez tiene la virtud de pretender ser igualitaria, pero que es muy inequitativa e ineficiente.

El CA de San Juan, de 1978, declara cerrados los padrones para nuevas concesiones de aguas superficiales, situación que ya se había decretado en 1974, por una emergencia hídrica. Desde entonces se han construido dos grandes embalses y otro se encuentra avanzado. También se ha rehabilitado y/o recrecido buena parte de los canales matrices del sistema de riego del Valle del Tulum. El riego localizado ha llegado a usarse en el 23\% de la superficie cultivada. Todo esto supone grandes ahorros de agua. Sin embargo, la agricultura sigue llevándose más del 90\% de las asignaciones de agua y, peor aún, aunque existen 15.000 ha de cultivos fuera de la red de riego, es decir, regados exclusivamente con agua subterránea, la superficie cultivada en el valle está estancada desde hace 100 años en unas 90.000 ha.

El DH sostiene que el sistema está preparado para una entrega volumétrica si los regantes la aceptaran. En base al conocimiento de la cuenca del Río San Juan y los pronósticos hídricos que se realizan anualmente, podrían asignarse volúmenes por hectárea concesionada, que serían entregados en función de las programaciones de riegos realizadas por las CR y las JR, y aprobadas por el Honorable Consejo del DH. Esto acercaría la curva de suministro a una demanda planificada. De todos modos, gestionar una red de riego tradicional a la demanda, con las características de la sanjuanina, con canales a cielo abierto que pasan por zonas urbanas donde la gente tira enormidad de basura, es harto complicado y sería difícil garantizar el suministro en tiempo y forma.

El sistema de riego del canal Calle 9 presenta unas condiciones casi ideales para incorporar un reservorio en cabecera, junto a la toma sobre el Canal Céspedes. Con las citadas flexibi- 
lizaciones de la inherencia y la modificación del coeficiente único por un método volumétrico, podría usarse ese reservorio como pulmón del canal, permitiendo a partir del mismo, entregas mucho más ajustadas a la demanda y con mayor garantía de suministro. Si a eso le sumamos el Uso Conjunto que ya prevé el CA, esas dotaciones podrían reforzarse con agua subterránea de perforaciones comuneras, reduciendo a su vez el volumen necesario del reservorio.

Las prácticas de reasignación del agua, tanto administrativas como de mercado, también deberían adquirir una estructura más formal de contabilidad y gestión, para una mayor transparencia y eficiencia. Pequeños mercados y/o bolsas de agua pueden funcionar, estando estas prácticas ya instituidas.

En caso de querer entregar agua presurizada, casi que bastaría con instalar una tubería paralela al canal. La diferencia de altura entre la toma y la cola del canal es de 55 metros, por lo que el gasto energético se vería minimizado. No sería necesario pasar a este sistema de una vez ni de manera compulsiva; ambas estructuras pueden convivir en paralelo. La entrega de agua presurizada produciría un importante ahorro a las fincas que ya cuentan con riego por goteo y necesitan reservorios y/o perforaciones, además de bombas, filtros, etc. La adopción de esta tecnología por parte de los otros regantes e vería facilitada tanto en el operativo como financiero.

Estas son sólo algunas opciones de diseño que repercutirían en una mayor productividad del agua y la mejora del nivel de vida del productor. Hay más, por ejemplo, vinculadas a los incentivos al ahorro a través de mecanismos diferenciados de tarifación del agua, que no vamos a analizar ahora.

\section{Conclusiones}

Nuestra intención es aportar, desde un enfoque institucional, algunos elementos a tener en cuenta a priori, es decir, antes de elaborar un proyecto o programa de modernización de regadíos. Dicha modernización debería contemplar como objetivos el ahorro de agua y su mayor productividad a través de asignaciones más orientadas a la demanda de los regantes y una gestión colectiva que permita las reasignaciones a nivel comunero.

En ese sentido, surge como imperativo revisar el Principio de Inherencia y la entrega por Coeficiente Único. El primero puede flexibilizarse en su reglamentación y así permitir las necesarias reasignaciones manteniendo sus virtudes de garantizar el valor de las inversiones. El Coeficiente Único, en cambio, sólo tiene la falsa virtud de la simpleza de dar a todos lo mismo en el mismo momento, por lo que no es compatible con una gestión moderna de los regadíos. Las dotaciones volumétricas con entrega flexible según demanda podrían reemplazar este sistema de coeficiente único.

El Uso Conjunto al que hace referencia el CA constituye una herramienta muy adecuada cuyo uso actual se minimiza por los costos asociados a la puesta en marcha y operación de las perforaciones necesarias. Un buen diseño institucional que internalice esos costos de manera equitativa sería deseable para su mejor implementación.

La actual estructura de gobierno del $\mathrm{DH}$ es totalmente compatible con la modernización. Las CR tienen el poder de decisión sobre cómo administrar el agua que les corresponde. Aunque no son Asociaciones de Usuarios que gestionan directamente el agua y los recursos de que disponen, las competencias otorgadas por el CA permiten hacer los ajustes correspondientes mediante una mayor y más activa participación formal de los regantes. 
Tal vez esto último sea el eslabón que precisa desarrollar unos incentivos más adecuados. Queda demostrado que los regantes se involucran constantemente en acciones colectivas, aunque sea informalmente, por lo que la cultura de buscar resultados que beneficien al grupo está presente.

\section{Referencias}

Bravo, G; Marelli, B. (2013): Irrigation systems as common-pool resources: Examples from Northern Italy, Journal of Alpine Research 96-3. URL: http://rga.revues.org/536; DOI: $10.4000 /$ rga.536.

Burt, C. (2001): "Rapid Appraisal Process (RAP) and Benchmarking: Explanation and Tools". ITRC Report No. R 01-008. ITRC. California Polytechnic State University. San Luis Obispo, California. 48 pp.

DH (2007): “Relevamiento Agrícola en la Provincia de San Juan Ciclo 2006 - 2007’. Departamento de Hidráulica, Gobierno de San Juan.

FAO (1997): "Modernization of irrigation schemes: past experiences and future options", Water Report Series 12, Bangkok.

Funes Rivas, MJ y Monferrer Tomás, J (2003): "Perspectivas teóricas y aproximaciones metodológicas al estudio de la participación" en Funes Rivas, M.J. y Adell Argiles, R (Eds.). Movimientos Sociales: cambio social y participación. Madrid, UNED.

Gonzalez Aubone, F. (2013): “La Administración del Agua para riego en San Juan”, en Cátedra Libre del Agua, Módulo V. INTA-UNSJ.

Ley No 886 de 1942, de Creación del Departamento de Hidráulica de la Provincia de San Juan. Modificada por: Ley $\mathrm{N}^{\circ}$ 959; Ley $\mathrm{N}^{\circ}$ 3131, Ley No 3334 y Ley No 6546. San Juan, Argentina.

Ley Nº 4392 de 1978, del Código de Aguas para la Provincia de San Juan. Texto Ordenado 1997 y Decreto Reglamentario 1479-MPI y MA/98. San Juan, Argentina.

Liotta, M. (2010): "Demanda Hídrica en la zona con derecho de riego en los Valles de Tulum, Ullum y Zonda". INTA EEA San Juan.

Liotta, M. (2011): "Requerimientos Hidricos de los Principales Cultivos en los Valles Centrales de la provincia De San Juan”. INTA EEA San Juan

Miranda, O; Graffigna, M.L.; Gonzalez Aubone, F. (2011): “Agua para el Desierto: Entendiendo los problemas de Acción Colectiva entre regantes de SJ (Argentina)". Estudios Sociales del Riego en la Agricultura Argentina. Capítulo VI. Ediciones INTA, pág.118-137. ISBN 978-987679-079-6.

Miranda, O.; Paz, M.; Gonzalez Aubone, F.; Andrieu, J. (2011): "El uso del agua para riego en la provincia de San Juan: una mirada territorial e institucional", Estudios socioeconómicos de la sustentabilidad de los sistemas de producción y recursos naturales $\mathrm{N}^{\circ} 16,32$ págs. ISSN 1851-6955. 
Miranda, O.; Gonzalez Aubone, F; Graffigna, M.L. (2012): “Gestión del agua para riego como Recurso de Uso Común (RUC): la buisqueda de un desempeño eficiente y sostenible a través de un enfoque institucional. El caso de la provincia de San Juan, Argentina", Libro de Actas de las VI Jornadas de Actualización en Riego y Fertirriego. Mendoza, Argentina.

Ostrom, E. (1990). "Governing the Commons: The Evolution of Institutions for Collective Action". Cambridge University Press. ISBN 978-0-521-40599-7.

Ostrom, E (1993): “Design Principles in Long-Enduring Irrigation Institutions". Water Resources Research, Volume 29, Issue 7, pages 1907-1912.

Pinto, M. (2004). "Mercados de agua y su posible implementación jurídica”. La Ley Gran Cuyo, pp. 87-96. Mendoza, Argentina. 